\title{
Organisational culture in construction: an employee perspective
}

Raufdeen Rameezdeen, Senior Lecturer, and Nishanthi Gunarathna, Research Assistant,

(Department of Building Economics, University of Moratuwa, Sri Lanka)

\section{ABSTRACT}

A large number of stakeholders in construction projects makes the construction industry prone to disputes. The historical separation between design and construction add to this phenomenon by having a consultant for design and a contractor for construction. Communication breakdown, frequently, is the first sign of problems, notably in the relationship between the Contractor and the Consultant. Therefore, it appears that the split between design and construction has given rise to two separate cultures in the construction industry. This paper attempts to identify whether there is a difference in organisational culture between Consultants and Contractors taken as two groups and determine whether a specific attribute was related to the cultural differences between the two entities. Based on case studies it was found that consultants are biased towards Clan culture while contractors are biased towards Market culture. However, both groups show similar affinity to Adhocracy and Hierarchy cultures.

Keywords-organisation, culture, consultant, contractor, competing value framework

\section{INTRODUCTION}

The common mode of procuring construction projects in Sri Lanka as well as many other countries could be explained using a model termed 'tripartite system'. The main three parties in a construction project are the Employer, the Consultant and the Contractor whose mutual responsibilities are defined by contractual and professional obligations. The formal nature of this relationship dates back to the colonial rule in Sri Lanka, and is regarded by its practitioners as the key to prudent project implementation in a market economy. It is designed to secure value for money through commercial competition, while protecting the legitimate interests of public finance and all concerned.

The term Employer covers the initiating agency which is responsible for providing funds for the execution of a project. The Employer inexperienced in the design and implementation of construction works seeks the advice of the Consultant. The Consultant is normally given two tasks by the Employer; the recommendation and justification of a preferred technical proposal together with an estimate of its cost, and further refinement of the design to the stage where tenders can be called for construction and the framework for site supervision can be established. Based on the competitive tendering system, a Contractor is selected for the physical execution of the project. Responsibilities of the
Contractor relate to the implementation of works specified in a formal contract, based on the consultant's designs. The relationships between the Employer-Consultant and the Employer-Contractor are governed by a formal contract. However, the Consultant-Contractor relationship is only a functional relationship which does not have contractual implications. Nevertheless, during the implementation stage of a project, the Consultant-Contractor relationship is very crucial for successful execution of the project. This historical separation of design and construction is well documented and considered as a prime cause for problems encountered in the construction industry (Egan, 1998; Bennett et al., 1996; Seymour and Rooke, 1995; Latham, 1994).

A preliminary investigation of disputes in the Sri Lankan construction industry was conducted to determine the root causes. Communication gap between the Consultant and Contractor was found to be the main reason for the majority of disputes (Fernando, 2002). Therefore, it appears that the separation of design and construction has given rise to two different cultures in the construction industry. These two entities work in watertight compartments and very few things can be seen in common. The desire to bring design and construction activity together is well established and has been generally welcomed by the industry (Root and Hancock, 1996). However, this is seen primarily as a redesign of the construction process through new contractual relationships, procurement routes and management tools (Seymour and Rooke, 1995).

Rameezdeen and De Silva (2002) have shown that adoption of these new procurement systems is difficult in countries like Sri Lanka where the traditional procurement system is well established. Eighty-five per cent of construction projects are still procured through the traditional system according to their estimate. It is increasingly accepted that "Culture "is a major element that hinders the integration of design and construction' (Latham, 1994; Egan, 1998; Fellows et al., 1994).

Within this context this paper aims to investigate whether there is a difference in the organisational culture of Consultants and Contractors taken as two groups, and to determine whether a specific attribute governs the cultural differences between the two entities. The research hypothesis to be tested is that:

'There is a difference in the organisational culture of Consultants and Contractors taken as two groups and this difference is due to some identifiable attributes'. 
It is important to note that the focus of this paper is limited to organisational culture, which is narrow in scope compared to the culture taken as a whole.

\section{ORGANISATIONAL CULTURE}

Organisational culture is identified as 'a collective programming of the mind which distinguishes the members of one organisation from another' (Hofstede, 1984). There is no doubt that different organisations develop different cultures. Sometimes it is fragmented and difficult to read from outside. According to Dawson (1996) it is 'shared values and beliefs that create distinctive patterns of thinking and feeling within organisations'. The author of Corporate Culture defined it as 'something historic, historically determined, related to the things anthropologists' study, socially constructed, soft and difficult to change. Some say it is something an organisation has, but also seen as something an organisation is' (Deal and Kennedy, 1982).

Cultures tend to emerge as an organisation discovers, invents, or develops solutions to the problems that it confronts. Successful approaches to solving problems tend to become a part of the culture and are used whenever similar conditions are faced (Schein, 1983). Further, it can be identified as 'the system of publicly and collectively accepted meanings operating for a given group at a given time' (Trice and Beyer, 1984). They emphasised the role that culture plays in helping people to decipher their world and highlighted that culture has two basic components, namely, substance and forms. Substance is the work practices, which are contained in organisational values, norms and beliefs. On the other hand, forms are expressed, affirmed and communicated to the members of the organisation.

Drennan (1992) defined culture as 'how things are done around here', and suggested that it is the company's internal environment that has the significant influence on employee attitude and not the external environment such as rising unemployment or global competition. Riley and Brown (2001) argued that culture is built up from many factors and is influenced by a range of variables that change over time. Culture develops through the normal and traditional methods by which things are done. The acceptable standards are established and become the norm. It is rooted in history, collectively held and sufficiently complex to resist attempts at direct manipulation.

The culture in an organisation is analogous to personality in an individual. Deal and Kennedy (1982) suggested that culture was the element that explained why companies differed so greatly, even those in the same industry. Most successful organisations have developed something special that supersedes corporate strategy, market presence or technological advances-a distinctive culture. Further they had identified five elements of organisational culture as: business environment; values and norms; heroes; rites and rituals; and communication. Byar (1987) pointed out four factors that contribute to the origin of an organisation's culture as its history, environment, staffing process and socialisation process. Since all organisations must interact with their environment, the environment plays an important role in shaping an organisation's culture. Organisations that operate within a highly regulated environment develop cultures totally different from organisations that face fierce competition in industries with rapidly changing technology.

Without valid means of measuring organisational culture, research into culture and its relationship with various factors and the environment is not possible. Further, it is essential to relate or link the measure to the business environment, especially in an industry like construction. Bowers (1969) highlighted five variables that composed culture and highlighted communication as being the most significant. Harrison (1972) proposed a model consisting of four basic variables namely 'power culture', 'role culture', 'task culture' and 'person culture'. In power culture, power and influence spread out from a central source. There may be a specialist or functional structure but central control is exercised largely through appointing loyal key individuals and exercising regular interventions from centre whim. Role culture, often referred as bureaucracy, works by logic and rationality. Procedures, role descriptions and authority definitions control work within and between departments of the organisation. Coordination is at the top-the senior management group. People are appointed to roles based on their ability to carry out the functions subject to satisfactory performance of role. Task culture is job or project oriented. The organisation operates by establishing terms to manage projects autonomously. There is high regard for experts in this culture and dependant on the right people being brought together at the right time, which is mainly associated with matrix structure. Person's culture is characterised by the fact that individuals can leave the organisation but the organisation seldom has power to evict individuals. Cultures like this can take on a life beyond the personal ambition of the members. It is also possible for person culture pockets to appear in large organisations.

Hofstede's (1991) studies on organisational culture identified six independent dimensions of practices such as Process oriented versus Result oriented, Job oriented versus Employee oriented, Professional versus Parochial, Open systems versus Closed systems, Rigidly versus Loosely controlled, Pragmatic versus Normative. The position of an organisation on these dimensions is determined by the business or an industry the organisation is in and the number of other 'hard' characteristics of the organisation. Deal and Kennedy (1982) classified organisational culture on the basis of two aspects: as the degree of risk associated with organisational activities; and the speed with which organisations and their employees get feedback indicating the success of decision. They identified four basic culture types according to their categorisation as 'tough guy/macho culture', 'work hard/play hard culture', 'bet your company culture' and 'process culture'. 
Maloney (1989) and Maloney and Federle (1991) presented a framework developed by Quinn (1988) and Cameron (1985) in terms of organisational culture, organisational effectiveness, leadership roles and management skills. Further, they presented the results of a study of organisational assessment that used a framework of competing values (Maloney and Federle, 1993), developed by Quinn and Cameron and proved that the methodology is valid. Hence, Competing Value Framework developed by Quinn and Cameron is a promising model for the measurement of organisational culture. This model is used in this study to determine the cultural differences between Consultants and Contractors in Sri Lanka.

The Quinn and Cameron approach is to ask the respondents to describe the organisation by how it functions, i.e., to describe the behaviours exhibited within the organisation. Based upon the description, the organisational culture is placed within a 'framework of cultures'. Results indicate perceptions of employees on their organisation.

As shown in Figure 1, the model dichotomises four different organisational culture types into a two-by-two matrix. There are four organisational culture types, namely Clan, Adhocracy, Market and Hierarchy. The axes for the quadrants illustrate the concept of Competing Values, in which the organisational culture types on the diagonals are 'competing' and those adjacent are 'complimentary'.

Organisations having a bias towards the upper half of the figure are considered to be oriented towards the decentralisation and differentiation, with an emphasis on spontaneity and flexibility. Organisations having a bias towards the bottom of the figure rely upon centralisation and integration, with an emphasis on predictability and order. Organisations, which are biased towards the left side of the figure, emphasise maintenance of socio-technical system, have an internal focus and utilise a long-term horizon. Organisations biased on the right side of the figure are oriented towards the competitive position of the overall system, have an external focus, and operate with short-term horizons. Thus, the values of the left side are competing with those of the right side.

Quinn (1988) describes the four organisational culture types that can exist in any organisation with different compositions as follows.

\section{Clan culture}

Clan culture is in the upper-left quadrant of the figure. It values emphasising openness, participation and discussion. The objective is to get everyone involved in activities and decisions of the organisations. Members of the organisation have a concern for other members and the organisation has a commitment to its members and their morale. Rewards are based upon group and organisational performance rather than individual performance. The organisation comes before the individual, who is a member of a team committed to the advancement of the organisation. The Clan emphasises flexibility and individual differences. It is characterised by teamwork and information sharing.

\section{Adhocracy culture}

The upper-right quadrant of the figure is labelled as the Adhocracy culture. It prizes external support, resource acquisition, and growth that it obtains through insight,

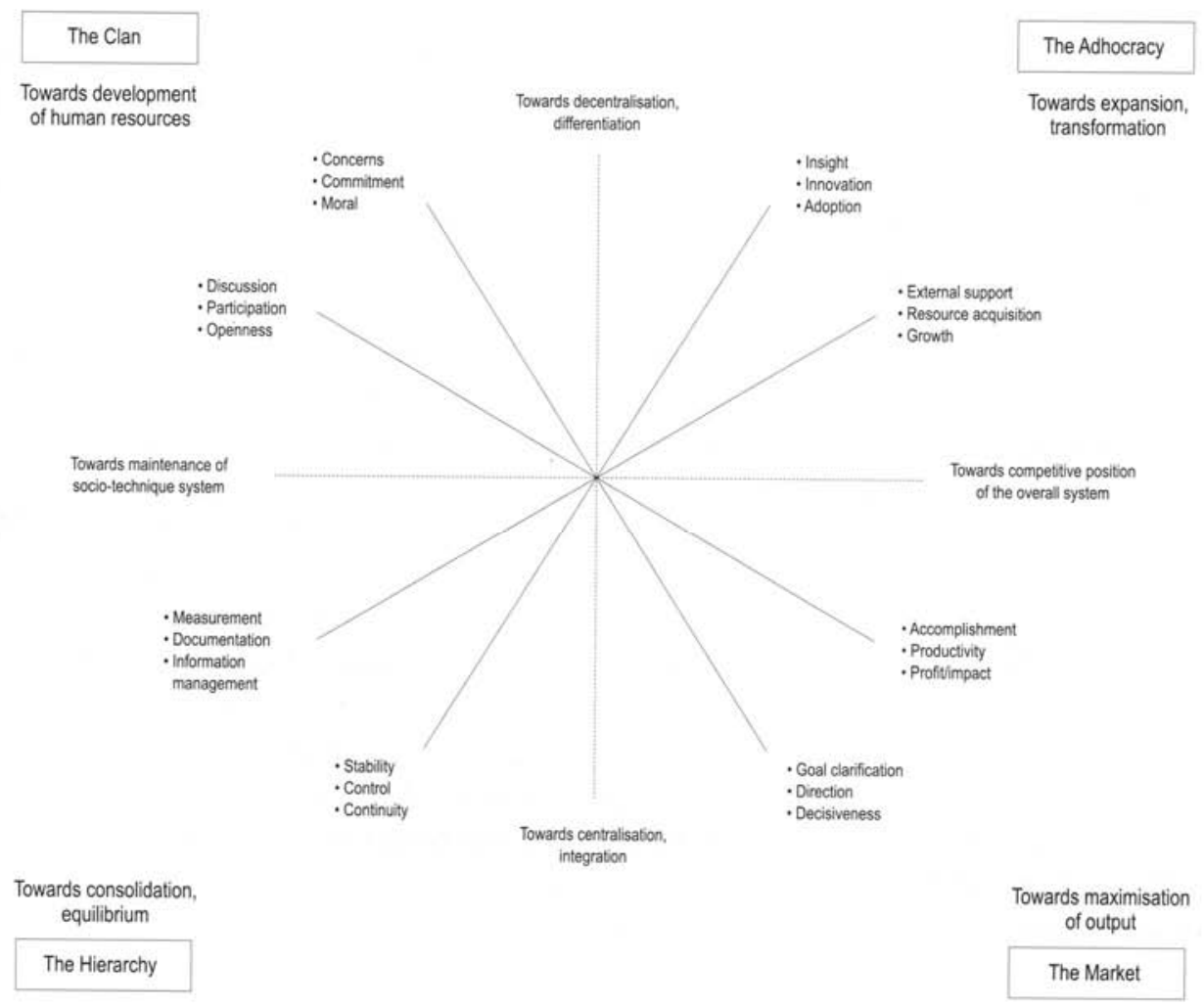


innovation, and adaptation. The emphasis is on innovation, looseness, and flexibility of structure in conjunction with a focus on external constituencies and resource providers and the achievements of legitimacy with outside stakeholders. Distinguishing features of the Adhocracy includes the prominence of entrepreneurial activity, creativity, and acquiring resources from external providers. There is a commitment to risk, innovation and development.

\section{Market culture}

Market is the term employed for the culture of a rational goal model organisation. This can be identified in the lower-right quadrant of the figure. With its emphasis on the maximisation of output, Market culture value goal clarification, providing direction, and being decisive about what is to be done. It prides itself on accomplishment and productivity and in making a profit or having an impact. It emphasises order, rational production, and goal accomplishment in combination with external interactions with suppliers, customers, subcontractors and competitors. The competitive orientation towards rivals and emphasis on achievements on the market place distinguish the Market from other cultures. Members of the organisation are clearly instructed by a decisive, authoritarian leader and are rewarded financially if they perform well. Rewards are based on individual performance rather than organisational performance.

\section{Hierarchy culture}

The hierarchy or bureaucratic culture is characteristic of the internal process and is based on consolidation and equilibrium. It is the antithesis of the Adhocracy culture. Hierarchy culture values stability, control and continuity, which are obtained through measurement, documentation, and information management. Maintenance of the internal system is of paramount importance. People are given well-defined roles and are expected to follow the rules and procedure that are developed to govern their actions. Situations are structured to fit the rules and procedures of the organisation. The major reward for the performance within the Hierarchy culture is job security. Financial rewards are primarily seniority based.

\section{CULTURAL ELEMENTS OF AN ORGANISATION}

Organisational culture can be considered as a cumulative representation of an assortment of elements. Quinn and Cameron identified six elements within the organisation to represent culture. These elements are briefly as follows.

\section{Dominant characteristics of the organisation}

Dominant characteristics can be considered as core values of the organisation. Clan culture values the importance of human resources while Market culture highlights the importance of exercising production-related strategies. Adhocracy culture place emphasis on enterpreneurship and core values of Hierarchy culture are formalised and structured characteristics of organisational activities.

\section{Style of the organisation leader}

To develop and maintain a culture, the leaders of an organisation must function in a manner consistent with the existing or desired culture of the organisation. Hence leadership styles are organised by culture types. Leaders of Clan culture act as mentors or parent figures of the organisation and in Market culture they act as hard drivers, producers or competitors. Adhocracy culture leaders function as entrepreneurs, innovators or risk takers and in Hierarchy culture they show the signs of coordinators or organisers in their work.

\section{Organisational glue}

These are espoused values or accepted norms of the organisation. Loyalty and traditions are key norms of the Clan culture while Market culture highlights the importance of goal accomplishment and production. Adhocracy culture values innovation and developments and in Hierarchy culture, every activity is governed by established rules and procedures of the organisation.

\section{Nature of organisational climate}

This explains existing working environment of the organisation. The climate of Clan culture is participative and comfortable while Market culture has a competitive and confrontational climate. Adhocracy culture has the characteristic of readiness and Hierarchy culture emphasises the state of performance and stability.

\section{Success criteria of the organisation}

This indicates the relationship between organisational success and the core values of it as perceived by the employees of the organisation. Clan culture believe that their success lies on the development of human resources while Market culture believes market penetration and existing market share as key reasons for their success. Adhocracy culture depends on project leaders to achieve success by implementing their innovative ideas. Hierarchy culture gives high weightage to smooth scheduling of organisational activities and strict time targets.

\section{Management style towards the employees}

For the effective development of a culture within an organisation, there is a necessity to have closer relationships between style of management and culture types. Management competencies possessed by the leaders should be consistent with the culture of their organisation. In Clan culture managers value teamwork, consensus and participation. Management style in Market culture is production oriented with incentives for achievement. In Adhocracy, employees taste freedom, innovation and uniqueness. Employees of the Hierarchy culture show security of the job and predictability as their main concern. 


\section{Data collection and analysis}

As described earlier, the 'Competing Value Framework', developed by Quinn and Cameron was used as a model for measurement of organisational culture.

The focus of the research was on entire organisation rather than on units of the organisation. Nine contractor organisations and nine consultant organisations in Sri Lanka participated in the study. The sample was selected with the aim of representing all types of consultant and contractor organisations who are engaged in construction work. Hence, selection ranged from small scale to multi-disciplinary construction organisations.

The questionnaire survey conducted for data collection included both executive and non-executive employees of the organisation from various divisions. Three executive employees and five non-executive employees were randomly chosen from an organisation for personal interviews and questionnaire survey and this ratio was maintained throughout the study. The executives of these organisations held titles such as Divisional Head, Project Manager, and Company Director. In total, 144 questionnaires and personal interviews were conducted equally for contractors and consultants.

The survey was carried out by obtaining prior appointments from the respondents and conducting the personal interview followed by the questionnaire survey. The objective of the personal interview was to solicit information related to the organisation, which would be useful in explaining the results of the questionnaire survey. In the questionnaire, four statements were utilised for each element, with one statement representing each of the four culture types based on the Competing Value Framework. Respondents were asked to distribute 100 points between the four statements for each element depending on how similar the description was to the organisation in question. The points distributed to each of the statements for the cultural elements were averaged to determine an overall culture score. A sample questionnaire and a sample of the results are contained in Appendix 1 and 2 respectively.

The responses were presented in a tabulated form for each organisation and summarised to obtain an overall score with the objective of comparing the overall culture of contractor and consultant organisations. Further, each element of organisational culture was analysed to determine the dominance and distribution of cultural types.

\section{Results of survey}

The results of analysis are presented under three headings as follows.

\section{Dominating culture types}

Table 1 summarises the dominating culture type for the six elements under consideration. Dominating culture type is the one that obtained the highest value when respondents were asked to distribute 100 points among the statements representing the four culture types. Five out of the six elements have Clan as the dominating culture type for consultants. All six elements of the contractors are dominated by Market culture.

\begin{tabular}{|c|c|c|c|c|}
\hline Cultural element & Clan & Adhocracy & Market & Hierarchy \\
\hline $\begin{array}{l}\text { Dominant } \\
\text { characteristics }\end{array}$ & & & $\checkmark$ & - \\
\hline $\begin{array}{l}\text { Organisational } \\
\text { leader }\end{array}$ & - & & $\checkmark$ & \\
\hline $\begin{array}{l}\text { Organisational } \\
\text { glue }\end{array}$ & - & & $\checkmark$ & \\
\hline $\begin{array}{l}\text { Organisational } \\
\text { climate }\end{array}$ & - & & $\checkmark$ & \\
\hline Success criteria & • & & $\checkmark$ & \\
\hline $\begin{array}{l}\text { Management } \\
\text { of employees }\end{array}$ & - & & $\checkmark$ & \\
\hline
\end{tabular}

Table 1: Dominating culture type in each element of the contractor and consultant organisations

\section{Competing culture types for each element}

Figures 2-7 show the results for each of the six elements of the organisational culture considered in the study. Contractors perceive Dominant characteristics of the organisations as strongly Market oriented (see Figure 2). This shows that the core values of the contractor organisations are oriented towards production-related strategies, which is a main characteristic of the Market culture. The organisation leaders of the consultants show a bias towards Clan Culture while the organisation leaders of contractors tend to move towards Market Culture as in Figure 3. This contrasting scenario explains that the leaders of consulting organisations are considered as mentors or parent figures while the leaders of contractor organisations are considered as hard drivers.

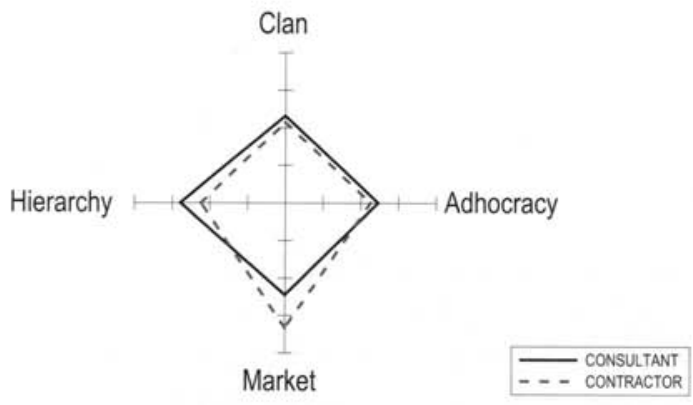

Figure 2: Dominant characteristics

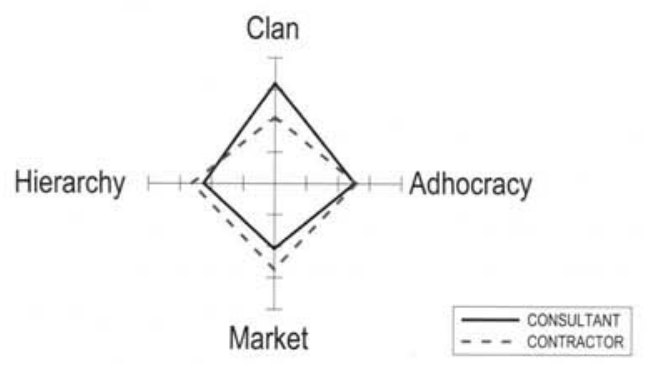

Figure 3: Organisational leader 
Organisational glue, which indicates the espoused values of the organisation also shows similar results to organisational leader as given in Figure 4. This shows that consultants value traditions and loyalty while contractors value goal accomplishment and production, which are the main espoused values in Clan and Market cultures respectively. The Organisation climate of consultants is strongly biased towards Clan and Adhocracy Cultures, while contractors organisation climate is biased towards Market and Adhocracy Culture types (see Figure 5). This shows that the working environment of consultants is participative and flexible. In contrast, the working environment of contractors is considered as competitive and confrontational, but flexible enough to provide room for innovation.

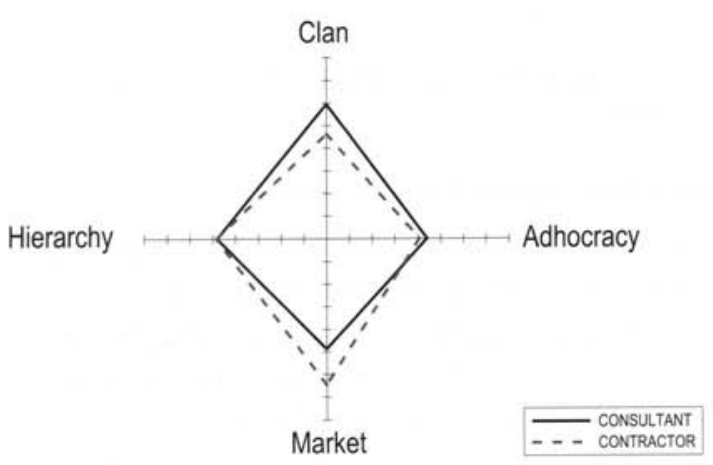

Figure 4: Organisational glue

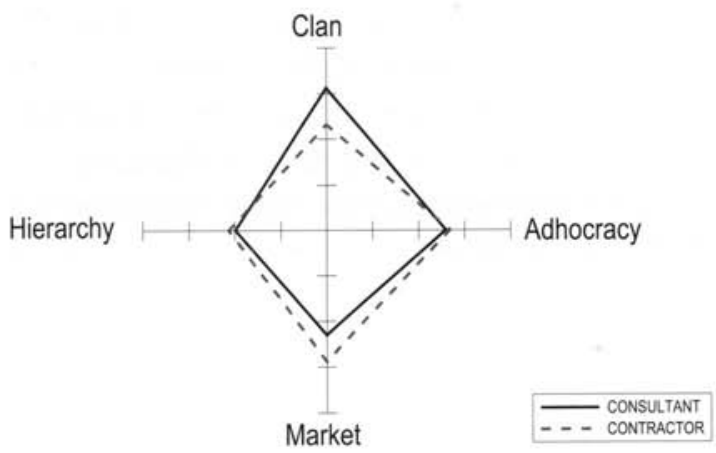

Figure 5: Organisational climate

The success criteria of consultants are perceived to be Clan oriented, while that of contractors are Market oriented with an inclination towards Hierarchy as in Figure 6 . This shows consultants believe that their success lies on the development of human resources which is a distinct feature of Clan culture. Contractors on the other hand, believe market penetration and market share as their success criteria with an added emphasis on smooth scheduling of organisational activities and strict time targets, which are distinct features of Market and Hierarchy cultures.

The results for Management style towards the employees, as given in Figure 7, shows a clear bias of Clan and Market culture types for consultants and contractors respectively. Consultants employ teamwork and participatory approach in managing their workers while contractors employ incentives for achievements.

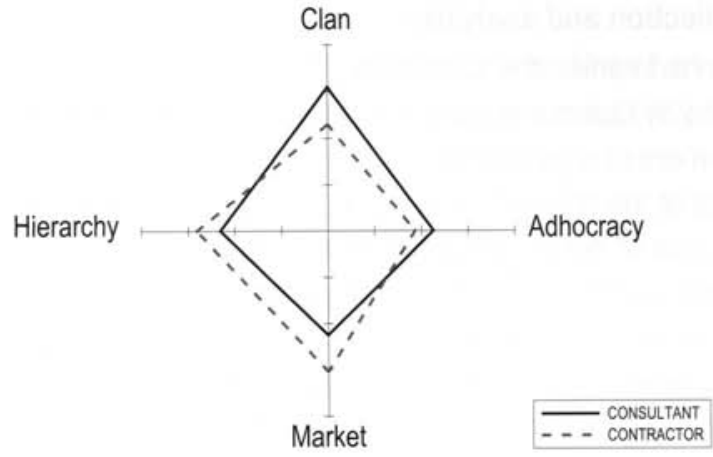

Figure 6: Success criteria

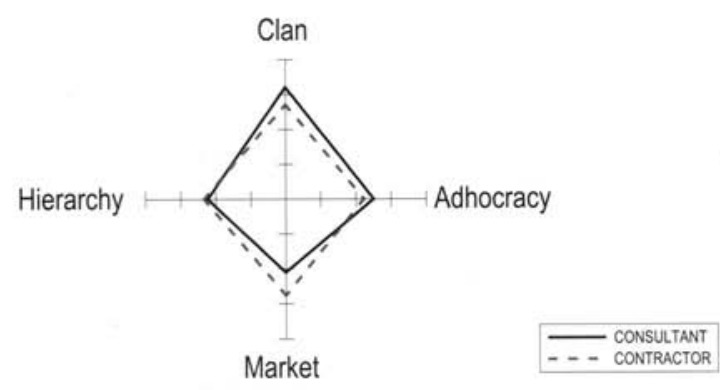

Figure 7: Management style

\section{Overall culture}

The overall culture profile, which is taken by averaging the six elements, illustrates that the Consultants are biased towards Clan culture while Contractors are biased towards Market culture. Both categories of organisations show similar affinity to Hierarchy and Adhocracy culture. Consultants prefer teamwork and rewards are based on group rather than individual. Consultants also show preference for information sharing, participative and comfortable working environment. Contractors on the other hand, emphasise profit maximisation and productivity. The competitive orientation towards rivals and emphasis on achievement make the contractors culture opposite of consultants. Similar affinity on competing values between Hierarchy and Adhocracy indicates that both contractors and consultants value entrepreneurship, innovation, coordination and organisation of work in equal terms.

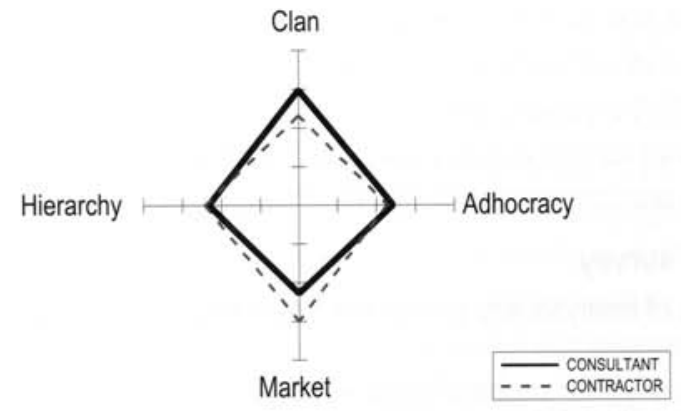

Figure 8: Overall culture profile 


\section{DISCUSSION}

In order to test the hypothesis set out in the first section of this paper, the characteristics within groups are considered first. Table 2 presents the mean values and standard deviation of the overall culture scores of these organisations.

\begin{tabular}{|l|c|c|c|c|}
\hline \multirow{2}{*}{} & \multicolumn{2}{|c|}{ Consultants } & \multicolumn{2}{c|}{ Contractors } \\
\hline & Mean & $\begin{array}{c}\text { Standard } \\
\text { deviation }\end{array}$ & Mean & $\begin{array}{c}\text { Standard } \\
\text { deviation }\end{array}$ \\
\hline Clan & 30.2 & 3.3 & 22.8 & 3.1 \\
\hline Adhocracy & 24.2 & 1.6 & 23.0 & 1.6 \\
\hline Market & 22.5 & 1.9 & 30.0 & 2.7 \\
\hline Hierarchy & 23.1 & 2.7 & 24.1 & 3.1 \\
\hline
\end{tabular}

Table 2: Within group characteristics

The mean value of consultants is highest for Clan culture and lowest for Market culture. However, the high standard deviation of Clan culture indicates the relative disagreement of ideas among consultants regarding their dominant culture. It appears that there were few who did not strongly believe that the dominant culture of consultants is Clan. The mean value of contractors is highest for Market and lowest for Clan and Adhocracy cultures. Relatively moderate standard deviation for Market indicates less disagreement among contractors on their dominant culture. Based on these 'within group' characteristics, it can be concluded that the consultants show a Clan dominated culture mix, while contractors show a Market dominated culture mix. The above inference could be made for contractors with a higher degree of confidence than for consultants.

To answer the question 'is there a difference between consultants and contractors with regard to their culture?', the difference between two sample means has been considered. As the two sample means are normally distributed it is assumed that the difference between the two means is also normally distributed. Using the following formula, confidence interval for the difference between the two means is calculated.

- $(\mu \mathrm{a}-\mu \mathrm{b}) \pm$ sc s.e. $(\mu \mathrm{a}-\mu \mathrm{b})$

Where,

- $(\mu \mathrm{a}-\mu \mathrm{b})$ is the difference between the two sample means $\mathrm{C}$ is the desired level of confidence

- s.e. $(\mu \mathrm{a}-\mu \mathrm{b})$ is the standard error of the difference between two means, which is given by [(sa2/na-1) + $(\mathrm{sb} 2 / \mathrm{nb}-1)] 1 / 2$

Where,

- $\mathrm{s}$ and $\mathrm{n}$ denotes the sample standard deviation and sample size respectively $(n=144)$.

Table 3 provides the confidence interval for all four culture types at $95 \%$ and $99 \%$ levels.

\begin{tabular}{|l|c|c|c|c|}
\hline & \multicolumn{2}{|c|}{$95 \%$ confidence interval } & \multicolumn{2}{c|}{ 99\% confidence interval } \\
\hline Cultural type & Lower limit & Upper limit & Lower limit & Upper limit \\
\hline Clan & 6.6 & 8.1 & 6.4 & 8.3 \\
\hline Adhocracy & 0.9 & 1.6 & 0.7 & 1.7 \\
\hline Market & 7.0 & 8.1 & 6.8 & 8.3 \\
\hline Hierarchy & 0.3 & 1.7 & 0.1 & 1.9 \\
\hline
\end{tabular}

Table 3: Difference between the two sample means

The statistical test indicates that at $99 \%$ confidence level, the difference between the two entities range between 6.4-8.3 for Clan, 0.7-1.7 for Adhocracy, 6.8-8.3 for Market, and $0.1-1.9$ for Hierarchy. It can be inferred from the above test that the difference between consultants and contractors is relatively low in Adhocracy and Hierarchy cultures.

This difference is relatively high in Clan and Market cultures. This implies that there is a considerable difference between the cultures of consultant and contractor organisations. This difference is mainly between Clan and Market cultures respectively. Thus the attributes that can be used to distinguish the two types of organisations can be given in Table 4.

\begin{tabular}{|l|l|}
\hline Consultants & Contractors \\
\hline Leaders as mentors & Leaders as hard drivers \\
\hline Loyalty to the organisation & Production-related strategies \\
\hline Participative work environment & Market penetration \\
\hline Teamwork & Goal accomplishment \\
\hline Human resource development & Confrontational work environment \\
\hline Rewards based on group & Incentives for achievers \\
\hline
\end{tabular}

Table 4: Main distinguishing characteristics of consultants and contractors

\section{CONCLUSIONS}

The analysis presented in this paper confirms that there is a marked difference between organisational culture of consultants and contractors. The study revealed that consultants are oriented towards a Clan dominated culture mix, while contractors are oriented towards a Market dominated culture mix.

Consultants believe that their success lie in development of human resources for achieving specific goals of the organisation. They emphasise loyalty, value traditions and prepare a participative comfortable working environment. Further, they highlight the importance of teamwork; encourage discussions, participative decision-making and open communication. Leaders of consultant organisations successfully play the role of mentors and guide subordinates towards a common objective.

Contracting organisations on the other hand, are driven towards output maximisation. They encourage a competitive work environment and emphasise goal accomplishment. Leaders of contractor organisations are considered as hard drivers. 
Both types of organisations have almost equal commitment to risk, innovation and development and face situations where tasks are not clearly defined despite severe deadlines. However, there are instances which totally fit with rules and procedures of the organisation as well. Hence, both types of organisations agree with the importance of maintaining their internal system.

Shaping the business activities to meet the demanding environment is a prerequisite in any organisation strategy. Hence, the difference between the organisational culture of consultants and contractors and the attributes that lead to this difference are understandable. However, the prime concern is the prevalence of disputes and communication gap between these two groups in the industry. The question is whether the organisational culture aggravates this situation. Can organisation culture be used to diffuse the tension between these two groups and as a result reduce disputes?

Further research is needed to address these issues and to find a solution to this pressing problem of construction disputes.

\section{REFERENCES}

Bennet, J. Pothecary, E. and Robinson, G. (1996).

Designing and Building a World-Class Industry. Center for Strategic Studies in Construction, University of Reading, Reading.

Bowers, D.G. (1969). Work Organisations as Dynamic Systems. Technical Report, Institute of Social Research, University of Michigan, Ann Arbor, Michigan.

Byar, L.L. (1987). Strategic Management Planning and Implementation: Concepts and Cases. 2nd edition, Harper and Row Publishers, New York.

Cameron, K.S. (1985). Cultural Congruence, Strength and Type: Relationships to Effectiveness. Working Paper Series 401, University of Michigan Business School, Ann Arbor, Michigan.

Dawson, S. (1996). Analysing Organisations. 3rd edition, Macmillan Press Ltd, Hampshire.

Deal, T.E. and Kennedy, A.A. (1982). Corporate Cultures: The Rites and Rituals of Cooperate Life. Addison-Wesley.

Drennan, D. (1992). Transforming Company Culture. McGraw-Hill, London.

Egan, J. (Construction Task Force) (1998). Rethinking Construction. DETR.

Fellows, R.F. Seymour, D. and Hancock, M.R. (1994). Conflict Resulting From Cultural Differentiation: An Investigation of the New Engineering Contract. Construction Conflict: Management and Resolution (edited by P. Fenn), 259-268. CIB Publication 171, Netherlands.
Fernando, N.P.N. (2002). Effect of Communication Barriers in Construction Disputes. Unpublished Final Year Dissertation of the B.Sc. Quantity Surveying Degree, Department of Building Economics, University of Moratuwa, Moratuwa.

Harrison, R. (1972). Understanding Your Organisation's Character. Harvard Business Review, May-June, 119-128.

Hofstede, G. (1984). Culture's Consequences: International Differences in Work Related Values. Sage, London.

Hofstede, G. (1991). Cultures and Organisations. McGrawHill, London.

Latham, Sir M. (1994). Constructing Team: Joint Review of Procurement and Contractual Arrangements in the United Kingdom Construction Industry. HMSO.

Maloney, W.F. (1989). Organisational Culture: Implication for Management. Journal of Management in Engineering, 5(2), 125-138.

Maloney, W.F. and Federle, M.O. (1991). Organisational Culture and Management. Journal of Management in Engineering, 7(1), 43-57.

Maloney, W.F. and Federle, M.O. (1993). Practical Models for Organisational Assessment. Journal of Management in Engineering, 9(1), 64-81.

Quinn, R.E. (1988). Beyond Rational Management: Mastering the Paradoxes and Competing Demands of High Performance. Jossey-Bass, San Francisco, California.

Rameezdeen, R. and De Silva, S. (2002). Trend of Construction Procurement Systems in Sri Lanka. Built-Environment Sri Lanka, 2(1), 2-9.

Root, D. and Hancock, M. (1996). Familiarity and Procurement Preference-Putting the Brake on the Adoption of New Procurement Methods. Economic Management of Innovation, Productivity and Quality in Construction, 11, CIB W-55, Sagreb, 523-534.

Riley, M.J. and Brown, D.C. (2001). Comparison of Cultures in Construction and Manufacturing Industries. Journal of Management in Engineering. 17(3), 149-158.

Schein, E.H. (1983). The Role of the Founder in Creating Organisational Culture. Organisational Dynamics, Summer, 13-28.

Seymour, D. and Rooke, J. (1995). The Culture of the Industry and the Culture of Research. Construction Management and Economics, 13(6), 511-523.

Trice, H.M. and Beyer, J.M. (1984). Studying Organisational Cultures Through Rites and Rituals. Academy of Management Review, 9, 653-669. 


\section{TOPIC: Organizational Culture in Construction: An Employee Perspective}

Note: Please be good enough to distribute 100 points between the four questions under each issue depending on how similar the description was to the organization in question.

\section{General Questions:}

1.The name of the organization

2. The type of organization (Consultant / Contractor)

\section{Specific Questions:}

a) Issue One: The dominant characteristics of the organization

1. How the organization sees the importance of human resources?

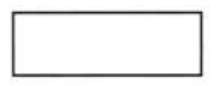

2. Does the organization value the entrepreneurship?

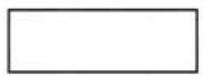

3. What is the organization standing on formalised and structured characteristics in organizational activities?

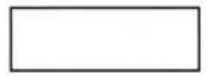

4. What is the organizations place on production related strategies?

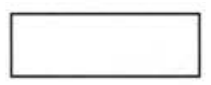

b) Issue Two: The behaviour of organization leader

1. Does the organization leader acting as Mentor, sage or parent figure?

2. Does the organization leader function as entrepreneur, innovator, or a risk taker?

3. Does the leader shows the signs of coordinator, organizer, or an efficiency export in his work?

4. Does the organization leader work as hard $Đ$ drive, producer, or a competitor?

c) Issue Three: The way of achieving organizational glue

1. Does the loyalty and traditions create organization glue?

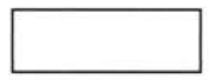

2. Does the innovation and developments create organization glue? 
3. Can the rules and regulation create organization glue?

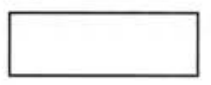

4. How the goal accomplishment and production make the organization glue?

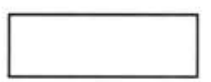

d) Issue Four: The climate of the organization

1. Does the organization climate is participative and comfortable?

2. Does the organization have the characteristics of dynamism and readiness?

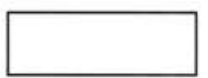

3. Does the organization have the state of performance and stability?

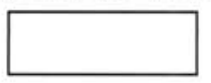

4. Does the organization experiencing competitive and confrontational climate?

e) Issue Five: Success criteria of the organization

1. Does the sensitivity to customers and concern for people have led to organizations success?

2. Does the state of product leader and innovator leads to organizations success?

3. How the dependable delivery and smooth scheduling create organization success?

4. Have the market penetration and market share led to organization success?

f) Issue Six: The style of management practice

1. Does the managers value on team work, consensus, and participation?

2. Does the employees taste the freedom, innovation and uniqueness?

3. How does the employees weight on security of the job and predictability?

4. Does the management use production oriented or achievement oriented management style?

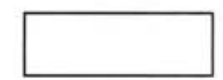


APPENDIX 2A: SAMPLE RESULTS FOR CONSULTANT ENGINEERS

\begin{tabular}{|c|c|c|c|c|c|c|c|c|c|c|c|}
\hline \multicolumn{12}{|l|}{ Consultant Organization 1} \\
\hline CULTURAL ELEMENT & \multicolumn{4}{|c|}{ EXECUTIVES(a) } & \multicolumn{6}{|c|}{ NON - EXECUTIVES(b) } & $\begin{array}{l}\text { OVERALL CULTURE } \\
((\mathrm{a}+2 \mathrm{~b}) / 3)\end{array}$ \\
\hline Dominant Characteristics & $\mathrm{A}$ & $\mathrm{B}$ & $\mathrm{C}$ & AVG & A & B & $\mathrm{C}$ & $\mathrm{D}$ & $\mathrm{E}$ & AVG & Average \\
\hline Clan & 29 & 23 & 19 & 23.67 & 21 & 24 & 20 & 11 & 18 & 18.80 & 20.42 \\
\hline Adhocracy & 22 & 18 & 11 & 17.00 & 30 & 28 & 28 & 27 & 24 & 27.40 & 23.93 \\
\hline Hierarchy & 25 & 32 & 41 & 32.67 & 25 & 20 & 21 & 30 & 28 & 24.80 & 27.42 \\
\hline Market & 24 & 27 & 29 & 26.67 & 24 & 28 & 31 & 32 & 30 & 29.00 & 28.22 \\
\hline \multicolumn{12}{|l|}{ Organizational Leader } \\
\hline Clan & 42 & 22 & 26 & 30.00 & 26 & 27 & 29 & 24 & 22 & 25.60 & 27.07 \\
\hline Adhocracy & 30 & 24 & 33 & 29.00 & 33 & 30 & 29 & 26 & 30 & 29.60 & 29.40 \\
\hline Hierarchy & 20 & 23 & 19 & 20.67 & 24 & 21 & 20 & 29 & 20 & 22.80 & 22.09 \\
\hline Market & 8 & 31 & 22 & 20.33 & 17 & 22 & 22 & 21 & 28 & 22.00 & 21.44 \\
\hline \multicolumn{12}{|l|}{ Organizational Glue } \\
\hline Clan & 32 & 22 & 20 & 24.67 & 31 & 22 & 29 & 24 & 26 & 26.40 & 25.82 \\
\hline Adhocracy & 15 & 21 & 22 & 19.33 & 19 & 22 & 27 & 20 & 20 & 21.60 & 20.84 \\
\hline Hierarchy & 35 & 24 & 28 & 29.00 & 26 & 26 & 21 & 26 & 25 & 24.80 & 26.20 \\
\hline Market & 18 & & 30 & 27.00 & 24 & 30 & 23 & 30 & 29 & 27.20 & 27.13 \\
\hline \multicolumn{12}{|l|}{ Organizational Climate } \\
\hline Clan & 44 & & & & 29 & 20 & 28 & a & 30 & 27.20 & 28.80 \\
\hline Adhocracy & 27 & 26 & 27 & 2 & 27 & 24 & 27 & 200 & 21 & 23.80 & 24.76 \\
\hline Hierarchy & 7 & & 27 & 33. & 19 & ت्रा & 21 & 25 & 25 & 24.00 & 22.11 \\
\hline Market & 22 & 15 & 32 & 23.00 & 25 & 26 & 24 & 26 & 24 & 25.00 & 24.33 \\
\hline \multicolumn{12}{|l|}{ Success Criteria } \\
\hline Clan & 53 & 42 & 23 & 39.33 & 28 & 29 & 30 & 28 & 30 & 29.00 & 32.44 \\
\hline Adhocracy & 12 & 7 & 25 & 14.67 & 21 & 28 & 26 & 24 & 20 & 23.80 & 20.76 \\
\hline Hierarchy & 26 & 24 & 21 & 23.67 & 27 & 23 & 20 & 28 & 27 & 25.00 & 24.56 \\
\hline Market & 9 & 27 & 31 & 22.33 & 24 & 20 & 24 & 20 & 23 & 22.20 & 22.24 \\
\hline \multicolumn{12}{|l|}{ Management of Employees } \\
\hline Clan & 14 & 21 & 27 & 20.67 & 23 & 29 & 30 & 27 & 27 & 27.20 & 25.02 \\
\hline Adhocracy & 38 & 23 & 19 & 26.67 & 31 & 29 & 27 & 21 & 24 & 26.40 & 26.49 \\
\hline Hierarchy & 22 & 32 & 31 & 28.33 & 25 & 22 & 23 & 31 & 29 & 26.00 & 26.78 \\
\hline Market & 26 & 24 & 23 & 24.33 & 21 & 20 & 20 & 21 & 20 & 20.40 & 21.71 \\
\hline \multicolumn{12}{|l|}{ OVERALL } \\
\hline Clan & & & & 28.39 & & & & & & 25.70 & 26.60 \\
\hline Adhocracy & & & & 22.22 & & & & & & 25.43 & 24.36 \\
\hline Hierarchy & & & & 25.44 & & & & & & 24.57 & 24.86 \\
\hline Market & & & & 23.94 & & & & & & 24.30 & 24.18 \\
\hline
\end{tabular}




\begin{tabular}{|c|c|c|c|c|c|c|c|c|c|c|c|}
\hline \multicolumn{12}{|l|}{ Contractor Organization 1} \\
\hline CULTURAL ELEMENT & \multicolumn{4}{|c|}{ EXECUTIVES (a) } & \multicolumn{6}{|c|}{ NON - EXECUTIVES (b) } & OVERALL $((a+2 * b) / 3)$ \\
\hline Dominant Characteristics & $\mathrm{A}$ & $\mathrm{B}$ & $\mathrm{C}$ & AVG & A & $\mathrm{B}$ & $\mathrm{C}$ & $\mathrm{D}$ & $E$ & AVG & Average \\
\hline Clan & 28 & 24 & 26 & 26.00 & 27 & 24 & 25 & 27 & 25 & 25.60 & 25.73 \\
\hline Adhocracy & 12 & 16 & 11 & 13.00 & 16 & 15 & 18 & 20 & 21 & 18.00 & 16.33 \\
\hline Hierarchy & 28 & 30 & 30 & 29.33 & 25 & 29 & 27 & 29 & 26 & 27.20 & 27.91 \\
\hline Market & 32 & 30 & 33 & 31.67 & 32 & 32 & 30 & 24 & 28 & 29.20 & 30.02 \\
\hline \multicolumn{12}{|l|}{ Organizational Leader } \\
\hline Clan & 26 & 24 & 24 & 24.67 & 23 & 20 & 28 & 27 & 26 & 24.80 & 24.76 \\
\hline Adhocracy & 14 & 18 & 20 & 17.33 & 15 & 16 & 17 & 19 & 20 & 17.40 & 17.38 \\
\hline Hierarchy & 29 & 30 & 27 & 28.67 & 30 & 31 & 24 & 25 & 25 & 27.00 & 27.56 \\
\hline Market & 31 & 28 & 29 & 29.33 & 32 & 33 & 31 & 29 & 29 & 30.80 & 30.31 \\
\hline \multicolumn{12}{|l|}{ Organizational Glue } \\
\hline Clan & 10 & 49 & 18 & 18.67 & 26 & 21 & 23 & 27 & 25 & 24.40 & 22.49 \\
\hline Adhocracy & & 2. & 22 & 25,32 & 23 & 28 & 20 & 20 & 23 & 22.80 & 23.64 \\
\hline Hierarchy & 27 & 24 & 29 & 2.67 & 0 & 9 & 9 & 3 & 23 & 22.80 & 24.09 \\
\hline Market & & 3 & & 33 & 1 & 2 & 81 & 30 & 29 & 30.00 & 29.78 \\
\hline \multicolumn{12}{|l|}{ Organizational Climate } \\
\hline Clan & 18 & 18 & 22 & 19.33 & 9 & 24 & 18 & 26 & 25 & 24.40 & 22.71 \\
\hline Adhocracy & 29 & 29 & 28 & 28.67 & 27 & 30 & 30 & 28 & 27 & 28.40 & 28.49 \\
\hline Hierarchy & 24 & 23 & 20 & 22.33 & 12 & 13 & 20 & 15 & 18 & 15.60 & 17.84 \\
\hline Market & 29 & 30 & 30 & 29.67 & 32 & 33 & 32 & 31 & 30 & 31.60 & 30.96 \\
\hline \multicolumn{12}{|l|}{ Success Criteria } \\
\hline Clan & 24 & 23 & 26 & 24.33 & 24 & 23 & 25 & 27 & 25 & 24.80 & 24.64 \\
\hline Adhocracy & 16 & 15 & 15 & 15.33 & 16 & 16 & 20 & 18 & 17 & 17.40 & 16.71 \\
\hline Hierarchy & 29 & 33 & 27 & 29.67 & 30 & 29 & 22 & 25 & 29 & 27.00 & 27.89 \\
\hline Market & 31 & 29 & 32 & 30.67 & 30 & 32 & 33 & 30 & 29 & 30.80 & 30.76 \\
\hline \multicolumn{12}{|l|}{ Management of Employees } \\
\hline Clan & 23 & 28 & 27 & 26.00 & 23 & 24 & 20 & 25 & 21 & 22.60 & 23.73 \\
\hline Adhocracy & 20 & 24 & 23 & 22.33 & 25 & 25 & 25 & 25 & 24 & 24.80 & 23.98 \\
\hline Hierarchy & 27 & 20 & 20 & 22.33 & 24 & 22 & 24 & 20 & 26 & 23.20 & 22.91 \\
\hline Market & 30 & 28 & 30 & 29.33 & 28 & 29 & 31 & 30 & 29 & 29.40 & 29.38 \\
\hline \multicolumn{12}{|l|}{ OVERALL } \\
\hline Clan & & & & 23.17 & & & & & & 24.43 & 24.01 \\
\hline Adhocracy & & & & 20.33 & & & & & & 21.47 & 21.09 \\
\hline Hierarchy & & & & 26.50 & & & & & & 23.80 & 24.70 \\
\hline Market & & & & 30.00 & & & & & & 30.30 & 30.20 \\
\hline
\end{tabular}

